\title{
Factors that support successful transition to the community among women leaving prison in British Columbia: a prospective cohort study using participatory action research
}

\author{
Patricia A. Janssen PhD, Mo Korchinski RSW, Sarah L. Desmarais PhD, Arianne Y.K. Albert PhD, \\ Lara-Lisa Condello MA, Marla Buchanan PhD, Alison Granger-Brown PhD, Vivian R. Ramsden RN PhD, \\ Lynn Fels PhD, Jane A. Buxton MBBS MHSc, Carl Leggo PhD, Ruth Elwood Martin MD MPH
}

\section{Abstract}

Background: In Canada, the number of women sentenced to prison has almost doubled since 1995. In British Columbia, the rate of reincarceration is $70 \%$ within 2 years. Our aim was to identify factors associated with recidivism among women in British Columbia.

Methods: We prospectively followed women after discharge from provincial corrections centres in British Columbia. We defined recidivism as participation in criminal activity disclosed by participants during the year following release. To identify predictive factors, we carried out a repeated-measures analysis using a logistic mixed-effect model.

Results: Four hundred women completed a baseline interview, of whom 207 completed additional interviews during the subsequent year, contributing 395 interviews in total. Factors significantly associated in univariate analysis with recidivism included not having a family doctor or dentist, depression, not having children, less than high school education, index charge of drug offense or theft under $\$ 5000$, poor general health, hepatitis C treatment, poor nutritional or spiritual health, and use of cannabis or cocaine. In multivariate analysis, good nutritional health (odds ratio [OR] 0.52 [95\% confidence interval (CI) 0.35-0.76]), good spiritual health (OR 0.61 [95\% Cl 0.44-0.83]), high school education (OR 0.44 [95\% $\mathrm{Cl} 0.22-0.87]$ ) and incarceration for a drug offence versus other crimes (OR 0.30 [95\% $\mathrm{Cl} 0.12-0.79]$ ) were protective against recidivism.

Interpretation: Our findings emphasize the relevance of health-related strategies as drivers of recidivism among women released from prison. Health assessment on admission followed by treatment for trauma and associated psychiatric disorders and for chronic medical and dental problems deserve consideration as priority approaches to reduce rates of reincarceration.

I n British Columbia, the number of women incarcerated each year rose from 1656 in 2012 to 1989 in 2015, an increase of $20 \% .^{1}$ The rate of reincarceration is $40 \%$ within 1 year of release and $70 \%$ within 2 years. ${ }^{2}$ Women in provincial facilities have received sentences less than 2 years. In the federal system, there are over 500 women incarcerated, with another 550 under community release supervision. In the last 10 years, the number of women admitted to federal jurisdiction has increased by almost $40 \% .^{3}$ Fully one-third of this population is Indigenous. Between 2002 and 2012, the Indigenous women inmate population increased by $109 \% .^{3}$ Indigenous women represent the fastest-growing subgroup of incarcerated women under federal jurisdiction. ${ }^{3}$

Poor health among incarcerated women in Canada has been documented, with higher rates of mental health disorders, substance use, communicable disease, injury and death than among the general population. ${ }^{4,5}$ However, in the few studies to date on recidivism among women, the role of health-related factors has not been examined. ${ }^{6-9}$ We followed a cohort of women for 1 year after discharge from incarceration in a provincial corrections centre to understand factors that supported their successful reentry into society, that is, without reported reengagement in criminal activity.

\section{Methods}

We performed a prospective longitudinal cohort study to examine the impact of health and social factors on reincarceration among women after release from provincial corrections

Competing interests: None declared.

This article has been peer reviewed.

Correspondence to: Patricia Janssen, patti.janssen @ubc.ca CMAJ Open 2017. DOI:10.9778/cmajo.20160165 
centres. Our model was participatory action research, which mobilizes people who stand to benefit from the research to inform, develop or create social action to improve the quality of their lives and of those in their community. ${ }^{10}$ Formerly incarcerated women participated in the design of the study and the development of survey tools, conducted the baseline and follow-up interviews, and assisted in data analysis and interpretation of study findings.

\section{Setting}

We recruited women who left provincial correctional or remand centres in British Columbia between 2008 and 2010. These included the Alouette Correctional Centre for Women (a maximum-security prison in Maple Ridge, $48 \mathrm{~km}$ from Vancouver), the Surrey Pretrial Services Centre and the Prince George Regional Correctional Centre. Length of stay in these facilities averages 3 months and ranges from a few days to 24 months.

\section{Participants}

The only criterion for eligibility was discharge from a provincial correctional centre in British Columbia within the previous year.

\section{Protocol development}

The study protocol was conceived at forums held within the Alouette Correctional Centre for Women that had been initiated by incarcerated women to present personal stories. During a series of 10 forums and in surveys conducted by a peer research team in the Alouette Correctional Centre for Women, ${ }^{11}$ women identified health and social goals they believed would contribute to successful transition to the community: 1) improved relationships with children, family and partners, 2) improved peer and community support, 3) safe and stable housing, 4) improved access to primary health care, 5) increased job skills and relevant employment, 6) more exercise and better nutrition, 7) improved dental/oral health, 8) improved access to health education and 9) increased ability to contribute to society. ${ }^{12}$ To develop the survey tools, the coauthors and members of the peer research team developed questions relevant to each of the identified goals as well as sociodemographic variables, details of substance use and history of incarceration. These tools were piloted for usability first among other members of the peer research team, then among a random sample of women in the community. Wording was changed for clarity in response to the piloting (Appendix 1, available at www.cmajopen.ca/content/5/3/E717/suppl/DC1).

We hired a team of community-based peer researchers, themselves formerly incarcerated, to recruit and conduct interviews with participants. Each peer researcher attended a workshop on interviewing skills, guided by a manual and supported by a video entitled Women in the Shadows: a Guide for Interviewing Women on the Margins. ${ }^{13}$

\section{Recruitment}

Women were made aware of the study before release from provincial corrections centres through posters and by word of mouth. At the Surrey and Prince George centres, women were contacted by the peer researchers at the time of release or shortly thereafter. At release from the Alouette Correctional Centre for Women, women are routinely given a bus ticket to return to where they were arrested. A peer researcher waited at the bus terminal to invite women to participate in the study. Women were given a study brochure and a verbal explanation. After written consent was obtained, responses to the survey questions were recorded on paper forms, a process that took about 20 minutes. Participants received a \$20 gift certificate. Surveys were conducted in 6 urban (Vancouver, Surrey, Kelowna, Victoria, Nanaimo, Prince George) and 3 rural (Abbotsford, Chilliwack and Maple Ridge) settings in the province. These were the home communities of our peer researchers. Peer researchers conducted follow-up interviews at 3, 6, 9 and 12 months following the baseline interview (Appendix 2, available at www.cmajopen.ca/content/5/3/E717/suppl/DC1). They maintained contact with participants through cellphones, Facebook and word of mouth and by frequenting popular hangouts and shelters. Interviews took place in cafes, on the street, and in women's shelters and drop-in centres.

\section{Statistical analysis}

To identify associations between achievement of the health and social goals in the year following release and the probability of committing a criminal act in the 3 months before each interview, we performed a repeated-measures analysis using a logistic mixed-effects model with each participant's unique study number as a random nesting effect. Mixed-effects models allow for unbalanced and incomplete sample sizes at each follow-up point. This results in the inclusion of participants with different numbers of follow-up interviews while controlling for correlation among the responses from each individual at different time points. We defined recidivism as participation in criminal activity as disclosed by participants. We elected not to designate reincarceration as our outcome of interest as participants told us that incarceration depended on circumstances beyond their control, such as "luck," their skill at shoplifting and whether their associates could afford legal counsel and advocacy. We therefore chose to measure behaviour that could have resulted in arrest had it been detected. Criminal activity included theft, breaking and entering, driving- or drug-related offences, or breach of parole conditions. We set statistical significance at $p<0.05$, using a likelihood ratio test.

We tested the following variables for univariate associations with recidivism: age at incarceration, education, Indigenous status, marital status, number of children, criminal charge, health conditions (infection with hepatitis $\mathrm{C}$ virus, HIV or methicillinresistant Staphylococcus aureus, depression, anxiety, bipolar disorder and personality disorder) at baseline and follow-up, general health at follow-up (on a scale of 1 [poor] to 5 [excellent]), intention to find a family doctor at baseline, desire to learn more about health and nutrition at follow-up, quality of diet (on a scale of 1 [poor] to 5 [excellent]), spiritual health (on a scale of 1 [poor] to 5 [excellent]), dental care needs, hopes for relationships with partners, children, parents and/or friends, living circumstances, substance use, injection drug use, methadone use, expo- 
sure to violence and abuse, employment status, and support from peers or community. Women referred to good nutrition as eating 3 healthy, well-balanced meals per day. They defined spiritual health as feeling closer to God, attending Indigenous ceremonies, attending church or engaging in healing activities.

Factors significantly associated with recidivism univariately were analyzed in an exploratory predictive multivariable model. We reduced the full model by sequentially removing each variable and then assessing the change in log-likelihood of the model. At each step, the variable with the highest $p$ value for the likelihood ratio test was removed, followed by another round of model fitting until all variables in the model caused significant reductions in $\log$-likelihood $(p<0.05)$. We calculated $p$ values from likelihood ratio tests comparing the fit of the model (deviance) with the variable included versus the fit with the variable removed. Analyses were conducted with $\mathrm{R}$ statistical software, version 3.1.

\section{Ethics approval}

A certificate of approval was obtained from the University of British Columbia Behavioural Research Ethics Board before participant recruitment.

\section{Results}

Of the 405 women who met the eligibility criterion, 400 consented to participate and completed a baseline interview. Of the 400, 207 completed at least 1 follow-up interview during the subsequent year (Figure 1). The 207 women together contributed 395 interviews.

Study participants were on average 34.2 years of age (Table 1). Over half (109 ([52.6\%]) reported Indigenous ancestry. A total of 132 (63.8\%) were single, and 152 (73.4\%) had children. Most (167 [80.7\%]) were not educated beyond high school. All were proficient in English. The average duration of incarceration was 81.6 days. Women who were lost to follow-up were not different from those who remained in the study except that there was a smaller proportion of Indigenous women in the group lost to follow-up (Table 1).

Fourteen variables were associated univariately with recidivism (Table 2). Variables documented at recruitment included intention to find a family doctor, depression, not having children, less than high school education, and incarceration for theft under $\$ 5000$ or for a drug offence. Variables associated with recidivism measured at follow-up included poor general health, treatment for hepatitis C, lack of opportunity to learn about health, poor nutrition, poor spiritual health, not having a dentist and reported use of cannabis or cocaine (Figure 2).

In multivariable mixed-effects logistic regression, after women without complete data for the 14 variables of interest were excluded, 127 women remained in the analysis, contributing 198 interviews. Of the 127, 72 had 1 follow-up interview, 34 had 2 follow-up interviews, 17 had 3 follow-up interviews, and 1 had 4 follow-up interviews. Of the 198 interviews, 106 indicated that women had not committed a criminal act during the 3 months before the interview.
Among the variables associated with criminal activity, 4 emerged as being statistically significantly associated with the probability of committing a criminal act within the prior 3 months in the multivariable model: nutritional health, spiritual health, education level and incarceration for a drug offence (Table 3). The results suggest that, for every 1-point increase in nutritional health, the odds of having committed a criminal act in the previous 3 months were reduced by about $50 \%$, all other variables in the model being held constant. Similarly, for every 1-point increase in spiritual health, the odds were reduced by about $40 \%$. High school versus less than high school decreased the odds by about $56 \%$, and postsecondary versus less than high school decreased the odds by about $80 \%$. Finally, having been incarcerated for a drug offence versus having been incarcerated for other offences decreased the odds by $70 \%$.

\section{Interpretation}

We determined that successful transition to the community in our cohort of women was associated with factors related to health and access to health care services, education, drug of

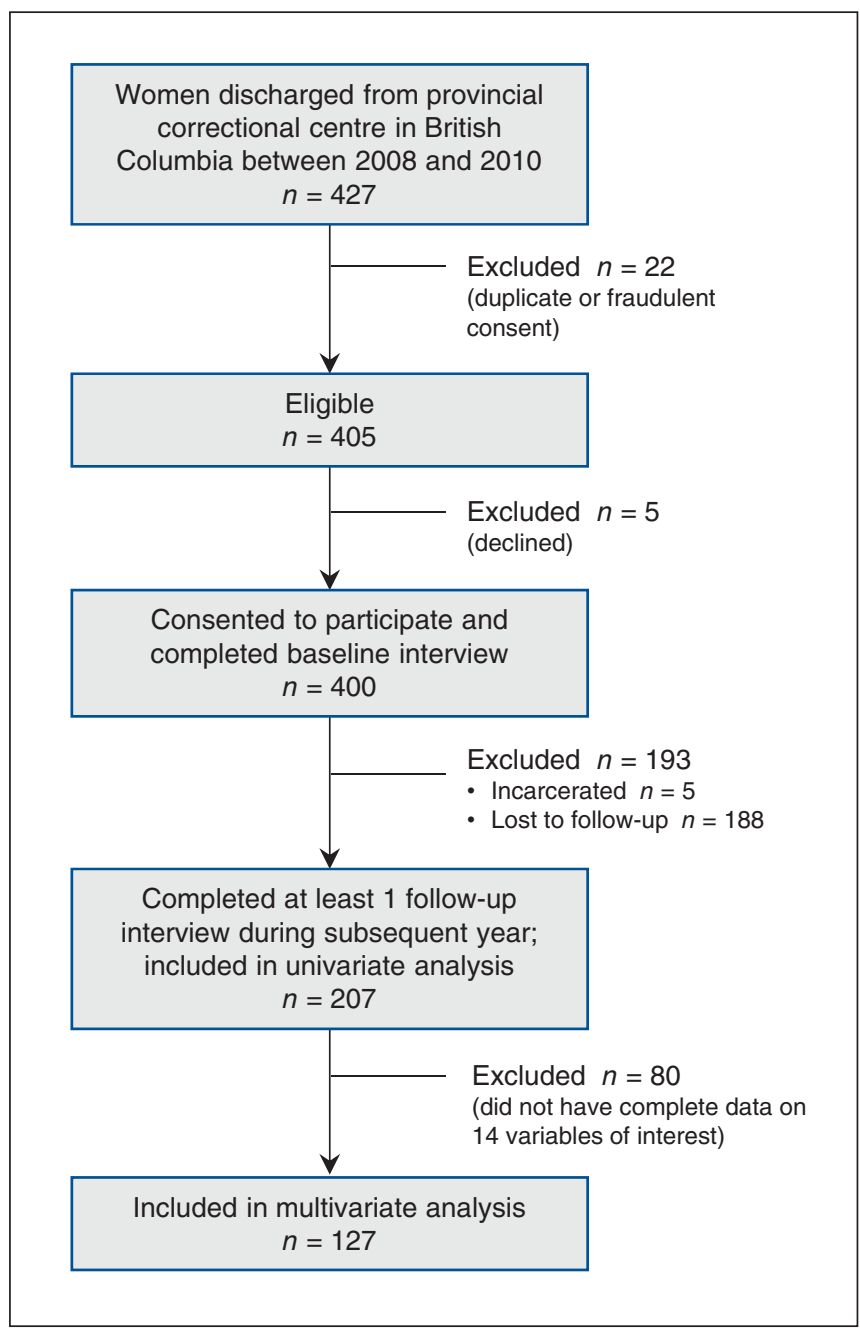

Figure 1: Flow diagram showing selection of study participants. 


\begin{tabular}{|c|c|c|c|}
\hline \multirow[b]{2}{*}{ Characteristic } & \multicolumn{2}{|c|}{ No. $(\%)$ of women* } & \multirow[b]{2}{*}{$p$ value } \\
\hline & $\begin{array}{c}\text { Participants } \\
n=207\end{array}$ & $\begin{array}{l}\text { Lost to follow-up/ } \\
\text { incarcerated } \\
n=193\end{array}$ & \\
\hline Age, mean $\pm S D, y r$ & $34.2 \pm 9.0$ & $33.2 \pm 9.5$ & 0.3 \\
\hline Indigenous status & 109 (52.6) & $67(34.7)$ & $<0.001$ \\
\hline Marital status & & & 0.4 \\
\hline Single & $132(63.8)$ & $118(61.1)$ & \\
\hline Married/common-law & $39(18.8)$ & $24(12.4)$ & \\
\hline Girlfriend/boyfriend & $21(10.1)$ & $31(16.1)$ & \\
\hline Separated/divorced & $11(5.3)$ & $6(3.1)$ & \\
\hline Widowed & $3(1.4)$ & $3(1.6)$ & \\
\hline Missing & $1(0.5)$ & $11(5.7)$ & \\
\hline Has children & $152(73.4)$ & $127(65.8)$ & 0.1 \\
\hline First language English & 191(92.3) & $175(90.7)$ & 0.7 \\
\hline Education & & & 0.8 \\
\hline$<$ High school & $101(48.8)$ & $84(43.5)$ & \\
\hline High school & $66(31.9)$ & $67(34.7)$ & \\
\hline Trade certificate/diploma & $6(2.9)$ & $8(4.1)$ & \\
\hline Some college/university & $16(7.7)$ & $19(9.8)$ & \\
\hline Completed college/university & $6(2.9)$ & $5(2.6)$ & \\
\hline Missing & $12(5.8)$ & $10(5.2)$ & \\
\hline Employed & $19(9.2)$ & $11(5.7)$ & 0.2 \\
\hline \multicolumn{4}{|l|}{ Reason for incarceration $†$} \\
\hline Theft $<\$ 5000$ & $65(31.4)$ & $51(26.4)$ & 0.6 \\
\hline Theft $\geq \$ 5000$ & $7(3.4)$ & $13(6.7)$ & 0.3 \\
\hline Assault & $44(21.2)$ & $17(8.8)$ & 0.002 \\
\hline Breaking and entering & $11(5.3)$ & $12(6.2)$ & 0.9 \\
\hline Drug-related offence & $48(23.2)$ & $63(32.6)$ & 0.1 \\
\hline Driving-related offence & $5(2.4)$ & $5(2.6)$ & 1.0 \\
\hline Breach of conditions & $65(31.4)$ & 70 (36.3) & 0.6 \\
\hline Injection drug use & $75(36.2)$ & $55(28.5)$ & 0.7 \\
\hline $\begin{array}{l}\text { Length of time in prison during } \\
\text { previous incarceration, mean } \pm \\
\text { SD, } d\end{array}$ & $81.6 \pm 94.2$ & $78.6 \pm 84.5$ & 0.7 \\
\hline $\begin{array}{l}\text { Note: } \mathrm{SD}=\text { standard deviation. } \\
\text { *Except where indicated otherwise. } \\
\text { †Participants could have more than } 1 \mathrm{re}\end{array}$ & & & \\
\hline
\end{tabular}

choice and the nature of the charge. Independent predictors included nutritional and spiritual health, education level and drug-related charges.

In a Canadian report on recidivism, the importance of family relationships, academic/vocational skills, employment, financial management and behavioural/emotional stability among women was noted, but health status was not reported on. ${ }^{2}$ In our study, health status and access to health care services after release proved more important than employment status or relationships. Our survey and those of other investi- gators ${ }^{4,14}$ indicate that many women did not have access to appropriate health care services before incarceration. As well, histories of childhood and adult sexual and physical abuse have contributed to trauma-associated mental health disorders. ${ }^{15}$ An early Canadian study of incarcerated women showed a rate of psychiatric diagnoses of $12 \% .{ }^{16}$ Trajectories in the drug trade have led to additional health problems. Women reported pain from damage to teeth after use of crack pipes, which, in turn, predisposed them to use opioids after release and to return to criminal activity. They also 


\begin{tabular}{|c|c|c|c|}
\hline \multirow[b]{2}{*}{ Variable } & \multicolumn{2}{|c|}{ No. $(\%)$ of interviews ${ }^{*} \dagger$} & \multirow[b]{2}{*}{ OR $(95 \% \mathrm{Cl}) \ddagger$} \\
\hline & $\begin{array}{l}\text { Criminal act } \\
n=168\end{array}$ & $\begin{array}{l}\text { No criminal act } \\
n=202\end{array}$ & \\
\hline General health, median (IQR)§ & $\begin{array}{l}3(2-3) \\
n=138\end{array}$ & $\begin{array}{l}3(3-4) \\
n=171\end{array}$ & $0.47(0.34-0.67)$ \\
\hline $\begin{array}{l}\text { Received treatment for hepatitis } C \text { in } \\
\text { previous } 3 \text { mo }\end{array}$ & $43(25.6)$ & $28(13.9)$ & $2.21(1.21-4.01)$ \\
\hline $\begin{array}{l}\text { Had opportunity to learn about health } \\
\text { in previous } 3 \mathrm{mo}\end{array}$ & $38(22.6)$ & $79(39.1)$ & $0.47(0.29-0.75)$ \\
\hline $\begin{array}{l}\text { Nutritional health in previous } 3 \mathrm{mo} \text {, } \\
\text { median (IQR)§ }\end{array}$ & $\begin{array}{l}3(2-4) \\
n=164\end{array}$ & $\begin{array}{l}3(3-4) \\
n=197\end{array}$ & $0.52(0.40-0.67)$ \\
\hline $\begin{array}{l}\text { Spiritual health in previous } 3 \mathrm{mo} \text {, } \\
\text { median (IQR)§ }\end{array}$ & $\begin{array}{l}4(2-4) \\
n=155\end{array}$ & $\begin{array}{l}3(3-5) \\
n=173\end{array}$ & $0.54(0.43-0.68)$ \\
\hline Has dentist & $26(15.5)$ & $50(24.8)$ & $0.54(0.31-0.92)$ \\
\hline Used cannabis in previous $3 \mathrm{mo}$ & $102(60.7)$ & $97(48.0)$ & $1.90(1.20-2.98)$ \\
\hline Used cocaine in previous $3 \mathrm{mo}$ & $103(61.3)$ & $90(44.6)$ & $2.19(1.38-3.48)$ \\
\hline \multicolumn{4}{|l|}{ Thought about finding family doctor } \\
\hline No & $40(23.8)$ & $27(13.4)$ & 1.00 \\
\hline Yes & $23(13.7)$ & $53(26.2)$ & $0.28(0.14-0.59)$ \\
\hline Already has one & $104(61.9)$ & $120(59.4)$ & $0.58(0.32-1.04)$ \\
\hline Depression & $36(21.4)$ & $65(32.2)$ & $0.57(0.34-0.93)$ \\
\hline Has children & $112(66.7)$ & $157(77.7)$ & $0.50(0.30-0.85)$ \\
\hline \multicolumn{4}{|l|}{ Education } \\
\hline$<$ High school & $93(55.4)$ & $81(40.1)$ & 1.00 \\
\hline High school & $55(32.7)$ & $73(36.1)$ & $0.65(0.41-1.04)$ \\
\hline Postsecondary & $8(4.8)$ & $37(18.3)$ & $0.19(0.08-0.43)$ \\
\hline Incarceration for theft under $\$ 5000$ & $64(38.1)$ & $56(27.7)$ & $1.65(1.01-2.70)$ \\
\hline Incarceration for drug offence & $15(8.9)$ & $48(23.8)$ & $0.30(0.16-0.58)$ \\
\hline \multicolumn{4}{|c|}{$\begin{array}{l}\text { Note: } \mathrm{Cl}=\text { confidence interval, } \mathrm{IQR}=\text { interquartile range, } \mathrm{OR}=\text { odds ratio. } \\
\text { "Twenty-five participants did not answer the question on criminal activity. } \\
\text { tExcept where noted otherwise. } \\
\text { †Reference is "no" unless specified otherwise. } \\
\text { §On a scale of } 1 \text { (poor) to } 5 \text { (excellent). }\end{array}$} \\
\hline
\end{tabular}

indicated that having missing or damaged teeth made finding work or housing nearly impossible. In addition to health concerns, spirituality has been reported as an important factor supporting women's transition to the community, particularly among Indigenous women. ${ }^{17}$ An Indigenous elder at the Alouette Correctional Centre for Women described Indigenous women seeking to learn about their people, then finding the courage to return to their community with dignity. ${ }^{18}$ Indigenous women accounted for $53 \%$ of our sample, in stark contrast to $4 \%$ among the Canadian population. ${ }^{19}$ Incorporation of culturally relevant and trauma-informed approaches to address the ongoing legacy of colonization and of the residential school system in this population may facilitate transition success. ${ }^{20,21}$

Lack of education was also identified as an independent predictor of recidivism in a US study.22 In Canadian provincial institutions in $2009,43 \%$ of female inmates were reported to have a high school diploma, and $12 \%$ had completed some postsecondary education. ${ }^{23}$ This underscores the need to offer education programs that can be continued after release. A qualitative study of incarcerated women identified health education as a priority need. ${ }^{24} \mathrm{~A}$ recent study of Canadian women's health literacy after release revealed limited ability to assess and make meaning of different sources of health information, particularly online information. ${ }^{25}$ This highlights the potential benefit of teaching online health literacy skills during incarceration; however, prisoners are not permitted to access the Internet. The protective effect of being a mother has been documented: ${ }^{26}$ concern about appropriate child care $^{27}$ is a strong deterrent to recommencing criminal activity. The number of children whose mothers are incarcerated in Canada is unknown. Our finding that incarceration for a drug offence 


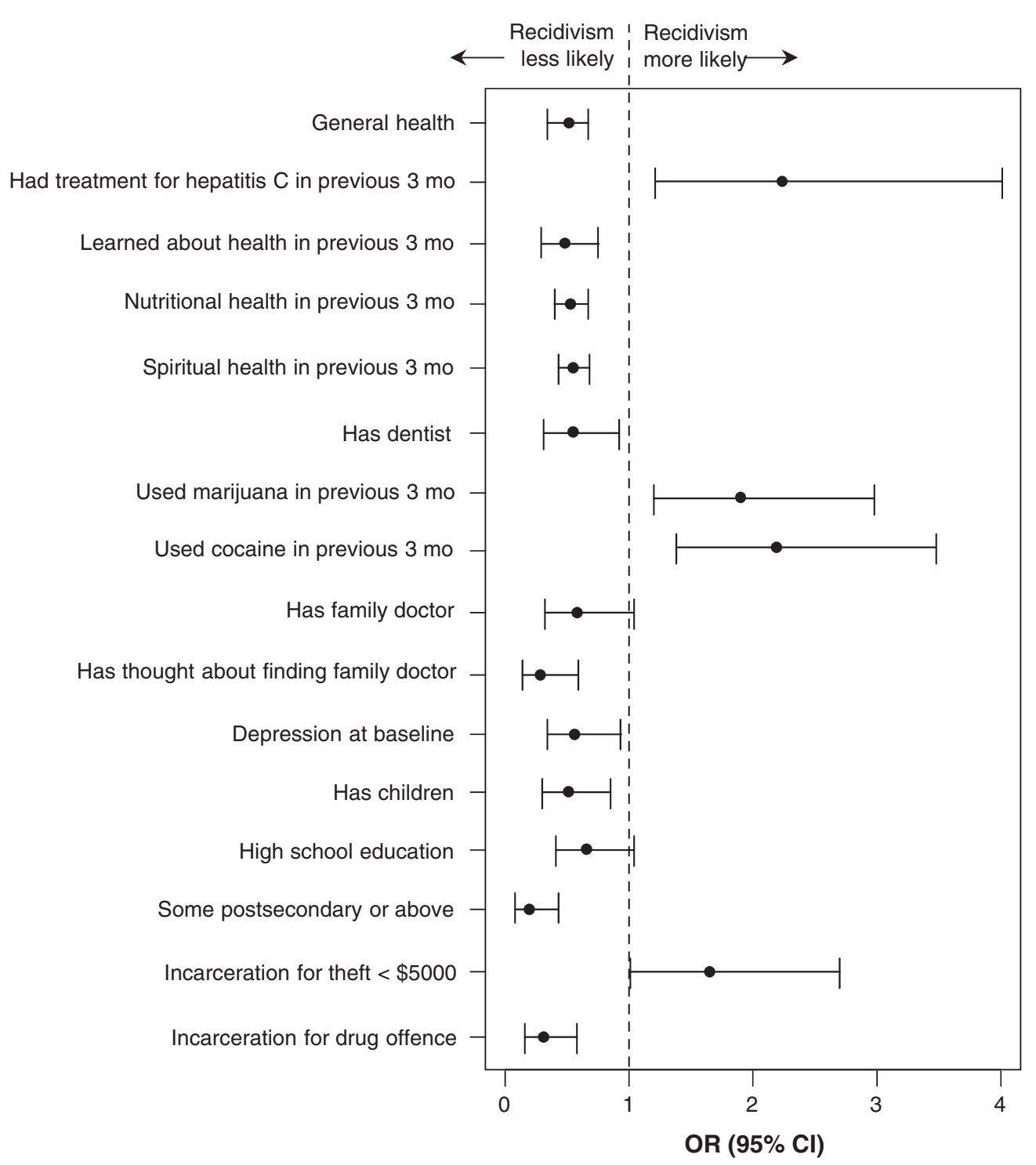

Figure 2: Variables associated on univariate analyses with recidivism in the 3 months before each interview. Note: OR $=$ odds ratio, $\mathrm{Cl}=$ confidence interval.

was associated with lack of recidivism appears at first to be counterintuitive. However, other charges included breaking and entering, assault and theft. Drug-related charges, in contrast, were not aimed at others or property and may have represented a lower level of criminality.

\section{Strengths and limitations}

A strength of our study was access to a representative sample. We recruited from all correctional centres for women in our province, and the sociodemographic characteristics of our sample were similar to those of the incarcerated population in Canada. ${ }^{28}$ The longitudinal design of our study allowed us to follow women to 1 year after release. We were also able to measure the risk of criminal activity as opposed to reincarceration, which is subject to factors separate from criminal activity. We feel that respondent bias was limited by our use of peer researchers.
Our study is limited by high rates of attrition. Given the nature of our study sample and the fact that we were able to support peer researchers in only 9 communities in the province, this loss was expected. With the exception of Indigenous status, women who were not located during the year after release were not different from those who were retained in the study. This suggests that missed interviews were unlikely to have substantively changed our findings. Our decision to report on self-reported criminal activity did not permit comparison with studies reporting on reincarceration. However, it resulted in higher sensitivity to detect our outcome of interest.

\section{Conclusion}

Our findings emphasize the relevance of health-related strategies to support successful reintegration into the community 
Table 3: Factors significantly associated with committing a criminal act in the multivariable model

\begin{tabular}{|c|c|c|}
\hline Variable & OR $(95 \% \mathrm{Cl})$ & $\begin{array}{c}\text { Likelihood } \\
\text { ratio test } \\
\text { statistic }\end{array}$ \\
\hline Good nutritional health & $0.52(0.35-0.76)$ & 12.1 \\
\hline Good spiritual health & $0.61(0.44-0.83)$ & 9.9 \\
\hline Education & - & 10.3 \\
\hline$<$ High school & 1.00 & \\
\hline High school & $0.44(0.22-0.87)$ & - \\
\hline Postsecondary & $0.20(0.06-0.70)$ & - \\
\hline $\begin{array}{l}\text { Incarceration for drug } \\
\text { offence }\end{array}$ & & 6.5 \\
\hline No & 1.00 & \\
\hline Yes & $0.30(0.12-0.79)$ & \\
\hline
\end{tabular}

for women leaving prison. Health assessment on admission followed by treatment for trauma and associated psychiatric disorders, as well as for chronic medical and dental problems, deserves consideration as priority approaches. According to our data, postrelease reinstatement of medical insurance coverage, referral to a primary care health provider, access to a dentist and funds to cover essential prescriptions would be critical components of reintegration. Given limited personal resources on release, there is a need for low-barrier health care clinics open 24 hours a day, 7 days a week.

\section{References}

1. Corrections adult custody dashboards. BC Ministry of Justice; 2017. Available: https://justicebcdashboard.bime.io/dashboard/adult/tab/13044 (accessed 2017 Mar. 4).

2. British Columbia Public Safety \& Solicitor General. Female and male community risk and needs assessment: data from Aboriginal offenders assessed in 1998. Victoria (BC) : British Columbia Corrections Branch; 2004.

3. Federally sentenced women. Ottawa: Office of the Correctional Investigator; 2017; Available: www.oci-bec.gc.ca/cnt/priorities-priorites/women-femmes -eng.aspx? texthighlight=Federally+sentenced+women (accessed 2017 Mar. 4).

4. Green S, Foran J, Kouyoumkjian F. Access to primary care in adults in a provincial correctional facility in Ontario. BMC Res Notes 2016;9:131.

5. Kouyoumdjian F, Schuler A, Matheson FI, et al. Health status of prisoners in Canada. Can Fam Physician 2016;62:215-22.

6. Greiner LE, Law MA, Brown SL. Using dynamic factors to predict recidivism among women: a four-wave prospective study. Crim Fustice Behav 2015; 42:457-80.

7. Rettinger LJ, Andrews DAS. General risk and need, gender specificity, and the recidivism of female offenders. Crim Fustice Behav 2010;37:29-46.

8. Matheson FI, Doherty S, Grant BA. Community-based aftercare and return to custody in a national sample of substance-abusing women offenders. Am $\mathcal{F}$ Public Health 2011;101:1126-32.

9. Dowden C, Blanchette K. An evaluation of the effectiveness of substance abuse programming for female offenders. Int 7 Offender Ther Comp Criminol 2002;46:220-30

10. Macaulay AC, Commanda LE, Freeman WL, et al. Participatory research maximises community and individual involvement. North American Primary Care Research Group. BM7 1999;319:774-8.

11. Martin RE, Murphy K, Chan R, et al. Primary health care: applying the principles within a community-based participatory health research project that began in a Canadian women's prison. Glob Health Promot 2009;16:43-53.

12. Ramsden V, Martin R, McMillan J, et al. Participatory health research within a prison setting; a qualitative analysis of 'Paragraphs of passion.' Glob Health Promot 2015;22:48-55

13. Korchinski M, Murphy K, Janssen P, et al. Women in the shadows: a guide for interviewing women on the margins. Vancouver: University of British Columbia;
2013. Available: https://www.youtube.com/watch?v=8Ua_fszixHc (accessed 2017 Mar. 4).

14. Mignon S. Health issues of incarcerated women in the United States. Cien Saude Colet 2016;21:2051-60.

15. Bloom B, Covington S. Addressing the mental health needs of women offenders. In: Gido R, Dalley L, editors. Women's mental health issues across the criminal justice system. Columbus (OH): Prentice-Hall; 2008:160-76.

16. Robertson RG, Bankier RG, Schwartz L. The female offender: a Canadian study. Can F Psychiatry 1987;32:749-55.

17. Parsons ML, Warner-Robbins C. Factors that support women's successful transition to the community following jail/prison. Health Care Women Int 2002;23:6-18.

18. Aboriginal Elder Marie Favant. "Holy cow." Aboriginal elder in prison. In: Martin RE, Korchinski M, Fels L, et al., editors. Arresting hope: women taking action in prison bealth inside out. Toronto: Inanna Publications and Education; 2014

19. Aboriginal peoples in Canada: First Nations people, Métis and Inuit. Ottawa: Statistics Canada; 2011. Available: https://www12.statcan.gc.ca/nhs-enm/2011/ as-sa/99-011-x/99-011-x2011001-eng.cfm (accessed 2017 Mar. 4).

20. Adelson N. The embodiment of inequity: health disparities in aboriginal Canada. Can 7 Public Health 2005;96(Suppl 2):S45-61.

21. Wesley-Esquimauz CC, Smolewski M. Historic trauma and aboriginal healing. Ottawa: Aboriginal Healing Foundation; 2004.

22. Uggen C, Krutschmitt C. Crime in the breaking: gender differences in desistance. Law Soc Rev 1998;32:339-66.

23. Mahony TH. Women and the criminal justice system. In: Women in Canada: a gender-based statistical report. Ottawa: Statistics Canada; 2015. Available: www. statcan.gc.ca/pub/89-503-x/2010001/article/11416-eng.htm (accessed 2017 Sept. 4).

24. Dinkel S, Schmidt K. Health education needs of incarcerated women. 7 Nurs Scholarsh 2014:46:229-34.

25. Donelle L, Hall J. An exploration of women offenders' health literacy. Soc Work Public Health 2014;29:240-51.

26. Freudenberg N, Daniels J, Drum M, et al. Coming home from jail: the social and health consequences of community reentry for women, male adolescents and their families and communities. Am 7 Public Health 2005;95:1725-36.

27. Wismont JM. The lived pregnancy experience of women in prison. 7 Midwifery Womens Health 2000;45:292-300.

28. Trevethan S. An examination of female inmates in Canada: characteristics and treatment [lecture]. Women in Corrections: Staff and Clients conference; 2000 Oct. 31-Nov. 1; Adelaide (Australia). Adelaide: Australia Institute of Criminology; 2000. Available: www.aic.gov.au/media_library/conferences/ womencorrections/trevetha.pdf (accessed 2017 Sept. 6).

Affiliations: Child \& Family Research Institute (Janssen); School of Population and Public Health (Janssen, Buxton, Elwood Martin); Collaborating Centre for Prison Health and Education (Korchinski, Condello, Elwood Martin), University of British Columbia, Vancouver, BC; Department of Psychology (Desmarais), North Carolina State University, Raleigh, NC; Women's Health Research Institute (Albert), BC Women's Hospital and Health Centre, Vancouver, BC; Nicola Valley Institute of Technology (Condello), Burnaby, BC; Counselling Psychology Program (Buchanan), Faculty of Education, and Centre for Group Counselling and Trauma, University of British Columbia, Vancouver, BC; Fielding Graduate University (Granger-Brown), Santa Barbara, Calif.; Academic Family Medicine (Ramsden), University of Saskatchewan, Saskatoon, Sask.; Arts Education (Fels) and International Centre of Arts for Social Change (Fels), Simon Fraser University; BC Centre for Disease Control (Buxton); Department of Language \& Literacy Education (Leggo), University of British Columbia, Vancouver, BC

Contributors: All of the authors contributed to the study conception and design. Mo Korchinski acquired the data, and Arianne Albert, Patricia Janssen, Mo Korchinski and Sarah Desmarais performed the data analysis. Patricia Janssen, Ruth Elwood Martin, Mo Korchinski, Sarah Desmarais, Marla Buchanan, Alison Granger-Brown, Vivian Ramsden and Lynn Fels interpreted the data. Patricia Janssen drafted the manuscript, and Ruth Elwood Martin, Mo Korchinski, Sarah Desmarais, Lara-Lisa Condello, Marla Buchanan, Alison Granger-Brown, Vivian Ramsden, Lynn Fels, Jane Buxton and Carl Leggo revised it critically for important intellectual content. All of the authors gave final approval of the version to be published and agreed to be accountable for all aspects of the work.

Funding: This study was funded by the Canadian Institutes of Health Research.

Supplemental information: For reviewer comments and the original submission of this manuscript, please see www.cmajopen.ca/content $/ 5 / 3 /$ E717/suppl/DC1. 